\title{
Knowledge of Diabetes Characteristics by Students at University of Tabuk, Saudi Arabia
}

\author{
Osama Alamri \\ Department of Statistics, University of Tabuk, Tabuk, KSA \\ Email: oalmughamisi@ut.edu.sa
}

How to cite this paper: Alamri, O. (2021) Knowledge of Diabetes Characteristics by Students at University of Tabuk, Saudi Arabia. Health, 13, 393-404.

https://doi.org/10.4236/health.2021.134032

Received: December 20, 2020

Accepted: April 18, 2021

Published: April 21, 2021

Copyright $\odot 2021$ by author(s) and Scientific Research Publishing Inc. This work is licensed under the Creative Commons Attribution International License (CC BY 4.0).

http://creativecommons.org/licenses/by/4.0/

\begin{abstract}
This is a study of university students' awareness of diabetes mellitus, and the extent of their knowledge about it. The research is a quantitative design based on a survey of students $(\mathrm{N}=700)$ at the University of Tabuk in the Saudi province of Tabuk. The findings were that the students' knowledge of diabetes indicators was encouraging, and that the faculty's periodic diabetes awareness programs should be continued to ensure that new students can recognise diabetes characteristics. In assessing variables for knowledge of the disease in relation to the demographics of people on the Tabuk University campus, marital status and weight were significant indicators. The conclusion was that awareness programs should be continued to avoid complacency and to combat the disease.
\end{abstract}

\section{Keywords}

Awareness Campaigns, Diabetes Mellitus, Kingdom of Saudi Arabia

\section{Introduction}

Diabetes mellitus is a complex metabolic disease, where risk of the disease passes from parents to their children through inherited genotypes (set of genes) and ethnicity; further, parents' lifestyles may add or reduce these risks [1]. People with diabetes experience fluctuating glycaemic (blood sugar) levels caused by inadequate or no insulin (hormone) production from the pancreas, thus the body cannot use the blood glucose it creates from carbohydrates for its energy. There is no definitive cure for diabetes and the condition must be continually managed to prevent organ damage or death [2]. People with diabetes have reduced ability to fight COVID-19, as comorbidities interfere with available virus treatments [3]; Alshareef, [4].

There are three predominant categories of diabetes, types 1 and 2, and gesta- 
tional. Type 1 diabetes is usually diagnosed whilst the person is young and occurs when there is little or no insulin produced. Insulin must be administered (injected) directly into the bloodstream to manage glucose levels [5]. Type 2 diabetes is a more common form, and is less severe than type 1. Other causes and effects occur beside insufficient insulin being produced, such as the insulin that is present in the bloodstream cannot adequately regulate glycaemic levels. Type 2 onset generally occurs with older people (over 45 years) and is associated with genetic background (family and ethnicity) and obesity. Gestational diabetes occurs with hormonal imbalances when pregnant and is usually managed by diet and exercise, Overall, diabetes can be managed for some through diet and regular exercise, although there is no permanent solution [2] [5].

This study was undertaken because Arabs are susceptible to diabetes mellitus, the disease contributes to reduced health and lifestyle, and a raised risk of developing comorbidities, including coronaviruses. Yet there is evidence that there is widespread apathy about diabetes in Saudi Arabia, as elsewhere, and that those with diabetes lack knowledge of self-management of the disease. As generations tend to live together, this is a study of Tabuk university students' awareness of diabetes mellitus, and the extent of their knowledge about it. This could be useful if they notice symptoms of the disease in their family members and take the responsibility to follow up on this. Tabuk University was selected for the sample due to its student profile and location in a regional province. Arguably, national awareness programs may not receive as much attention from the population as those in metropolitan locations. Thus, the purpose of the research is to assess the knowledge of people on the Tabuk University campus of diabetes mellitus characteristics in patients.

\subsection{Diabetes in Saudi Arabia}

The International Diabetes Foundation in 2019 reported that Saudi Arabia had 4.3 million people with diabetes, over 18 per cent of the adult population [6]. The Kingdom ranked $14^{\text {th }}$ from 195 countries for incidence of diabetes with a value of 15.8; examples of other countries include the small Pacific nation of Kiribati (population 125,000) with the highest value of 22.5, United States' value was 10.8, United Kingdom's 3.9, whilst countries in western Africa rated at 2.4 (Index Mundi 2020). Nevertheless, the Saudi General Authority for Statistics conducted a household health survey of the population in 2018, finding that $2,156,294$ people $(1,460,934$ Saudi nationals) over the age of 15 years stated that they had been diagnosed with diabetes, 87 per cent (90\% Saudis) were 40 years plus [7]. Diabetes was the $10^{\text {th }}$ highest cause of death in the Kingdom in 2019 [8].

Considerable variation in the susceptibility of populations to diabetes can be seen from country incidences, partly attributed to ethnic genotypes. Arabs are more susceptible to diabetes than other ethnic genotypes, and age, family history, obesity, and blood markers are potential risk factors [9]. For this reason, the Saudi government expends significant resources in alerting the public to re- 
main vigilant in detecting the signs of diabetes in themselves, friends, and family, and agencies also provide information on diet and promote opportunities for exercise in the Arabian Peninsula's arid climate [10].

\subsection{Characteristics of Diabetes}

Due to lifestyle practices, over half of type 2 diabetes is preventable [11]. An issue with this form of diabetes is that onset of the disease is generally associated with ageing, and indicators of the disease may be masked by pre-existing conditions (comorbidities). Diabetes leads to increased risk of cardiovascular disease, sight problems such as vision blurring/focus damage, hearing loss, nerve damage, skin conditions, and foot problems. These conditions occur naturally from ageing, or may be indications of other diseases [8] [11].

However, warning signs of incipient or existing type 2 diabetes include excessive thirst and frequent urination, numbness and/or tingling in feet and hands, obesity, dizziness, longer time for cuts to heal, or tiredness. Upon diagnosis of all diabetes, diet is predominant in control of glucose in the blood, as blood sugar rises and falls with daily activities, Thus foods and drinks intakes must vary with need for balance to prevent hypoglycaemia (low blood sugar) or hyperglycaemia (high blood sugar levels). When necessary, appropriate medication is taken either orally, or by subcutaneous injection into fatty tissue to be absorbed over time into the bloodstream. Unless unwell, vigorous daily exercise for 30 minutes each day is indicated to maintain muscle functions [11] [12] [13].

\section{Literature Review}

Awareness of the characteristics of diabetes among the Saudi population and even non-specialist healthcare professionals is low, despite considerable interest and promotion by medical researchers [14] [15] [16]. Interestingly. the findings were consistent at about 40 per cent of the general population who were reasonably knowledgeable about the characteristics of diabetes mellitus. For Mujammami [16] study, 37 per cent of the participants offered adequate correct responses, whilst [15] found that 39 per cent of women in their childbearing years were aware of gestational diabetes. All studies recommended more intensive diabetes awareness campaigns, with Mujammami [16] advocating for social media as well as traditional media outlets. Effective and ongoing awareness programs are crucial with chronic diseases such as diabetes [14] [15].

Adherence to day-to-day glycaemic regimes was also difficult for Saudis. Alramadan [17]. [18] surveyed patients with type 2 diabetes $(\mathrm{n}=1111)$ across Saudi Arabia and found inadequate glycaemic control. Lack of attention to health was attributed to advanced age, length of time with the disease, and adverse sociodemographic characteristics. Again, access to fresh vegetables and fruit, exercise, better knowledge about haemoglobin A1c (test for glycaemic levels). [11], stated that an urgent review of diabetes management plans was necessary to refocus on targeted factors. Again, these factors were supported by [14] in a study of food 
and drink sweetener preferences for people $(\mathrm{n}=302$, Riyadh) with type 2 diabetes. A majority of participants (57\%) used white sugar, less used honey (26\%) and only 12 per cent used artificial sweeteners. Opinion was that whilst artificial sweeteners could lower energy intake (25\%), 35 per cent of the sample believed them harmful [19].

Relating to the COVID-19 pandemic, Alramadan [17] studied incidence of diabetes in records of patients hospitalised with the Middle East respiratory syndrome (MERS-CoV) during the previous coronavirus epidemic in 2015-2016. Using extant medical data, they found that underlying and severe conditions, especially diabetes and hypertension, contributed to death. This was confirmed by in a literature review by [20] who reported that age, comorbidities, and frailty were also factors.

\section{Materials and Methods}

\subsection{Methodology}

A quantitative (mathematical) research design was selected for data collection and descriptive analysis using statistics. Quantitative research designs can be assessed for reliability, validated, and generalised to the population [21]. This design is therefore suitable to assess the knowledge of the characteristics of diabetes of people at the University of Tabuk.

\subsection{Research Plan}

The survey instrument was created by adapting questionnaires undertaken by [5] [11] [12] [14] and [19]. These surveys differed for populations, with different lifestyles and diets, so that in this study, similar questions were augmented by those particular to Tabuk. Thus, the questionnaire was shortened to improve acceptability to potential participants, and designed in two parts, one for demographics and the other consisting of 13 questions with simple yes/no or correct/incorrect measures. The questions were previously validated for construct by other researchers and face validity was established as the answers to the research problem. Similarly, the reliability of the questions follow standard practice for diabetes knowledge surveys, and these were adapted to meet translations needs, although the International Diabetes Foundation has Arabic language surveys ([11] [12] [14] [19]).

In the questionnaire's foreword, the participants were told that they would not be identified, and any personal information or an opinion was anonymous, and used only for the purpose of the research. Demographics questions comprised age, gender, married status (for testing inheritance and type 1 diabetes knowledge) weight (mass in kilograms), faculty, and nationality. Measures were commensurate with the questions, using five-year cohorts for age and 10-kilogram cohorts for mass. Personal healthcare regarding diabetes was also requested. Knowledge of characteristics of diabetes comprised 13 questions or statements across biological knowledge, symptoms, and relevant factual (or not) statements 
(thinking it through). As noted, the survey was offered for quick completion to encourage completion. It was designed in English, translated to Arabic and administered by email or paper according to preference, then translated back to English, and entered into Excel spreadsheet preparatory to analysis. All steps were carefully reviewed as part of the design process [21].

\subsection{Data Collection and Analysis}

The researcher lives in Tabuk City, which has a population of a half million people. The University of Tabuk services the province of Tabuk in the northwest of Saudi Arabia with a population about one million. In 2020, the university had 30,170 students and 1718 staff and was rated in the top 100 universities of the Middle East and North Africa region [22]. However, the Saudi statistics agency in 2018 stated that the university comprised 1829 faculty members plus 1086 administrators; 32,214 students were registered, and 5931 students had graduated in 2017 [23]. The university was representative of a population considered relevant to undergraduates' knowledge of the characteristics of diabetes mellitus.

The sample of study participants was selected on campus by convenience, and added to with further participants by requesting those who took a paper to forward on as an email (snowballing). Volunteer participants were asked if they were willing to fill out a questionnaire relevant to their knowledge of diabetes [24]. It was explained that this was to assess their knowledge of diabetes, as they were considered a sophisticated population and their responses would indicate factors in diabetes knowledge to focus upon for future local diabetes awareness campaigns. Due to the online snowballing effect, it was difficult to estimate how many people received the survey; it was closed when 700 completed responses were received, as this number was considered quite adequate to represent the university population. The data were collected from September to mid-December, 2019.

The sample size was dictated by the number of answers received within the timeframe. As noted, the sample was selected by convenience, and further responses were collected through social networks. Thus, the number of eventual recipients was unknown, but due to the large response rate, a cut-off was made at 700 valid responses, which represented about two per cent of the population on the university campus, although it is unknown if all respondents were students. The 700 valid surveys entered into the Microsoft Excel were transferred to a SPSS program (v.26) for quantitative analysis to produce descriptive and statistical results (IBM Training 2020).

Quantitative analysis consisted of deriving frequencies and percentages for the demographic data which were then subjected to inferential testing. Pearson's chi-squared test $\left(\chi^{2}\right)$ was used for goodness of fit to validate the analysis; homogeneity, to compare respondents (groups) in a selected variable; and independence to indicate whether respondent cohorts showed different responses [25]. 


\section{Results}

The demographic results, as noted, comprised age, gender, weight (mass), faculty and nationality of the sample of 700 people from the campus of the University of Tabuk. The descriptive analysis is shown at Table 1.

Table 1 shows that the participants were primarily unmarried (81.7\%), not local (from Tabuk) (71.6\%), and were women (67.1\%). The ages of participants varied, although many were aged up to 21 years (46.4\%). Interestingly, nearly one quarter was in their late twenties or older $(23.22 \%)$, so that they may have been graduate students or staff. Weight may be associated with height (body mass index) but this study was not medical research, so that the results were simply data for analysis. Reported weight of the participants was relatively distributed through the sample, with 29.1 per cent reporting of 51-60 kilograms, and 20.56 per cent reporting over 70 kilograms. The majority of participants were from science faculties (52.6\%), least of whom were in the Arabic language faculty (6.2\%). Participants also volunteered the information that two participants had type 1 diabetes and four had type 2 diabetes, 23 respondents; while only 3.3 per cent had been tested for diabetes.

The second part or the survey concerned the participants' knowledge of Table 1. Demographic data of participants $(n=700)$.

\begin{tabular}{|c|c|c|c|}
\hline Variable & Measure & $\mathbf{N}$ & Percentage \\
\hline \multirow{2}{*}{ Gender } & Male & 230 & 32.9 \\
\hline & Female & 470 & 67.1 \\
\hline \multirow{2}{*}{ Nationality } & Saudi (from Tabuk) & 199 & 28.4 \\
\hline & Other & 501 & 71.6 \\
\hline \multirow{3}{*}{ Age } & 21 years or under & 325 & 46.4 \\
\hline & $22-26$ years & 213 & 30.4 \\
\hline & 27 years or over & 162 & 23.2 \\
\hline \multirow{2}{*}{ Marital status } & Unmarried & 572 & 81.7 \\
\hline & Married & 128 & 18.3 \\
\hline \multirow{4}{*}{ Weight (mass) } & 40 - 50 kilograms or under & 185 & 26.4 \\
\hline & $51-60$ kilograms & 204 & 29.1 \\
\hline & 61 - 70 kilograms & 167 & 23.9 \\
\hline & Above 70 kilograms & 144 & 20.6 \\
\hline \multirow{6}{*}{ Faculty } & Sciences & 369 & 52.6 \\
\hline & Education & 61 & 8.7 \\
\hline & Business management & 53 & 7.6 \\
\hline & Arts & 60 & 8.6 \\
\hline & Engineering & 114 & 16.3 \\
\hline & Arabic language & 43 & 6.2 \\
\hline
\end{tabular}


characteristics of diabetes.

Table 2 shows that overall, participants had a good knowledge of the characteristics of diabetes. It was particularly interesting to note that nearly nine out of ten participants $(89.9 \%)$ correctly stated that diabetes was caused by inadequate or no insulin production by the pancreas; that low blood sugar may be caused by too much insulin in the body (63.7\%), and similarly, 69.6 per cent were aware that symptoms of tremors and sweating may indicate low blood sugar, a reaction from an insulin imbalance. Good knowledge was also found among the participants for threats to glycaemic levels if diabetes is not managed (84.6\%), and danger of cuts to feet $(81.9 \%)$. Further, 80.6 per cent of the participants were

Table 2. Diabetes awareness $(n=700)$.

\begin{tabular}{|c|c|c|c|}
\hline Characteristic & Response & $\mathbf{N}$ & $\%$ \\
\hline \multirow{2}{*}{ Sugar-rich foods are a risk for a person with diabetes } & Incorrect & 136 & 19.4 \\
\hline & Correct $^{*}$ & 564 & 80.6 \\
\hline \multirow{2}{*}{$\begin{array}{l}\text { Diabetes is primarily due to decreased secretion of } \\
\text { insulin by the pancreas }\end{array}$} & Incorrect & 71 & 10.1 \\
\hline & Correct $^{*}$ & 629 & 89.9 \\
\hline \multirow{2}{*}{ Does diabetes contribute to kidney disease? } & No & 285 & 40.7 \\
\hline & Yes $^{*}$ & 415 & 59.3 \\
\hline \multirow{2}{*}{ Blood sugar levels fluctuate if diabetes is left untreated } & Incorrect & 108 & 15.4 \\
\hline & Correct* & 592 & 84.6 \\
\hline \multirow{2}{*}{$\begin{array}{l}\text { If I have diabetes, my children have a higher chance of } \\
\text { developing diabetes }\end{array}$} & Incorrect & 223 & 31.9 \\
\hline & Correct $^{*}$ & 477 & 68.1 \\
\hline \multirow[b]{2}{*}{ There is currently no cure for diabetes } & Incorrect & 337 & 48.1 \\
\hline & & 363 & 510 \\
\hline \multirow{2}{*}{$\begin{array}{l}\text { Regular exercise increases the need for diabetes } \\
\text { medications }\end{array}$} & Incorrect* $^{*}$ & 578 & 82.6 \\
\hline & Correct & 122 & 17.4 \\
\hline \multirow{2}{*}{$\begin{array}{l}\text { Tremors and sweating may be signs of low blood sugar } \\
\text { (hypoglycaemia) from insulin imbalances }\end{array}$} & Incorrect & 213 & 30.4 \\
\hline & Correct $^{*}$ & 487 & 69.6 \\
\hline \multirow[b]{2}{*}{ Obesity is a major contributor to the onset of diabetes } & No & 168 & 24.0 \\
\hline & $\mathrm{Yes}^{\star}$ & 532 & 76.0 \\
\hline \multirow{2}{*}{$\begin{array}{l}\text { People with diabetes should take care when cutting } \\
\text { toenails }\end{array}$} & No & 127 & 18.1 \\
\hline & Yes $^{*}$ & 573 & 81.9 \\
\hline \multirow{2}{*}{$\begin{array}{l}\text { Frequent urination and excessive thirst are signs of } \\
\text { high blood sugar levels }\end{array}$} & No & 257 & 36.7 \\
\hline & $\mathrm{Yes}^{*}$ & 443 & 63.3 \\
\hline \multirow{2}{*}{$\begin{array}{l}\text { Low blood sugar may be caused by too much insulin } \\
\text { in the bloodstream }\end{array}$} & Incorrect & 254 & 36.3 \\
\hline & Correct* & 446 & 63.7 \\
\hline \multirow{2}{*}{ Compression socks are helpful for those with diabetes } & Incorrect & 509 & 72.7 \\
\hline & Correct* $^{*}$ & 191 & 27.3 \\
\hline
\end{tabular}

${ }^{\star}$ Indicates correct answer. 
aware that foods containing substantial amounts of sugar were a danger to people with diabetes, and that excessive body weight was a risk factor for diabetes $(76 \%)$. On the other hand, there was insufficient awareness that there is no direct cure for diabetes ( $48.1 \%$ thought there was a cure), nor was there sufficient knowledge of the risk of kidney disease from diabetes ( $40.7 \%$ were incorrect). Of concern, 82.6 per cent thought exercise a risk for those with diabetes, whereas the reverse is true; and a substantial proportion (72.7\%) thought that restrictions around the feet (compression socks) were another risk. About one-third were incorrect regarding thirst as a symptom of high glycaemic levels (36.7\%), and inheriting the disease $(31.9 \%)$.

Overall, there were 5834 correct responses to all the questions, or 64.1 per cent. Nevertheless, this was not consistent among the participants, as for the purposes of this study a minimum of eight correct answers was considered good general knowledge of diabetes. For this cohort, there were 552 (78.9\%) participants who were knowledgeable and 138 (21.1\%) who scored less than eight correct answers (see graph at Figure 1).

\section{Validation}

Table 3 shows the results of chi square tests for association between demographic variables and diabetes knowledge levels, Table 3 shows a statistically significant relationship $(\mathrm{p}<0.05)$ between diabetes knowledge and marital status, and knowledge and weight. The significance was shown as 85.2 per cent of married participants were correct, whilst 77.4 per cent of unmarried participants were correct. Similarly, where weight (mass) was the variable, rising awareness was displayed among the cohorts, with significant differences shown in the example of awareness of diabetes risk displayed by 87.5 per cent of those over 70 kilograms of weight. Otherwise, there was no statistically significant relationship between diabetes knowledge and other demographic categories at 95 per cent.

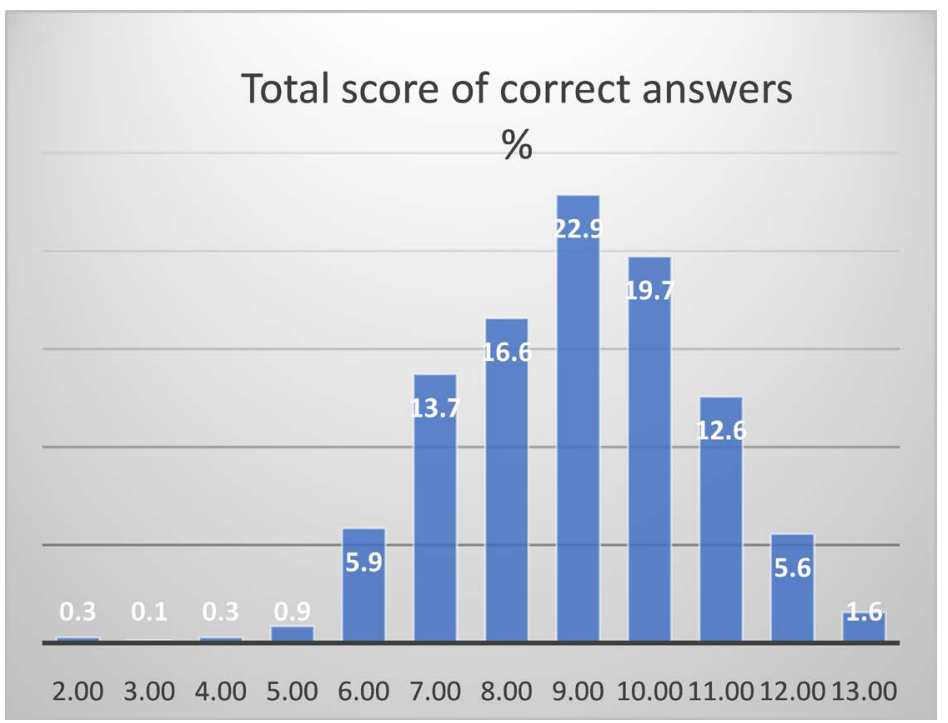

Figure 1. Distribution of correct answers from participants. 
Table 3. Results of statistical analysis.

\begin{tabular}{|c|c|c|c|c|c|}
\hline & Variable & Low knowledge & High knowledge & $x^{2}$ & $p$-value \\
\hline \multirow{2}{*}{ Gender } & Male & $19.6 \%$ & $80.4 \%$ & \multirow{2}{*}{0.511} & \multirow{2}{*}{0.475} \\
\hline & Female & $21.9 \%$ & $78.1 \%$ & & \\
\hline \multirow{3}{*}{ Age } & 21 years or under & $24.9 \%$ & $75.1 \%$ & \multirow{3}{*}{5.765} & \multirow{3}{*}{0.056} \\
\hline & $22-26$ years & $19.2 \%$ & $80.8 \%$ & & \\
\hline & 27 years or over & $16.0 \%$ & $84.0 \%$ & & \\
\hline \multirow[b]{2}{*}{ Status } & Unmarried & $22.6 \%$ & $77.4 \%$ & \multirow[b]{2}{*}{3.728} & \multirow{2}{*}{$0.032^{*}$} \\
\hline & Married & $14.8 \%$ & $85.2 \%$ & & \\
\hline \multirow{4}{*}{ Weight } & 50 kilograms or under & $28.1 \%$ & $71.9 \%$ & \multirow{4}{*}{11.839} & \multirow{4}{*}{$0.008^{* *}$} \\
\hline & 51 - 60 kilograms & $21.1 \%$ & $78.9 \%$ & & \\
\hline & 61 - 70 kilograms & $21.0 \%$ & $79.0 \%$ & & \\
\hline & Above 70 kilograms & $12.5 \%$ & $87.5 \%$ & & \\
\hline \multirow{2}{*}{ Nationality } & Saudi (from Tabuk) & $21.6 \%$ & $78.4 \%$ & \multirow{2}{*}{0.036} & \multirow{2}{*}{0.849} \\
\hline & Other & $21.0 \%$ & $79.0 \%$ & & \\
\hline \multirow{6}{*}{ Faculty } & Sciences & $20.9 \%$ & $79.1 \%$ & \multirow{6}{*}{4.562} & \multirow{6}{*}{0.472} \\
\hline & Education & $26.2 \%$ & $73.8 \%$ & & \\
\hline & Business Management & $18.9 \%$ & $81.1 \%$ & & \\
\hline & Arts & $26.7 \%$ & $73.3 \%$ & & \\
\hline & Engineering & $21.1 \%$ & $78.9 \%$ & & \\
\hline & Arabic language & $11.6 \%$ & $88.4 \%$ & & \\
\hline
\end{tabular}

${ }^{*}$ Significant at 0.05 level. ${ }^{*}$ Significant at 0.01 level.

\section{Discussion}

The findings of this study are that there is widespread knowledge of the characteristics of diabetes mellitus among people on the campus of the University of Tabuk. This does not agree with [14] or Mujammami et al. (2020) which were medical studies, nor does it agree with [15] which found a lack of awareness of gestational diabetes. In the extant studies, there was a global level of diabetes' characteristics awareness of about 40 per cent. However, it was higher for this research where Figure 1 depicts more respondents' knowledge in the higher ranges, and in fact nearly two-thirds (64.1\%) of the questions were correctly answered. The reasons for this could be that Tabuk is a provincial city and regular awareness campaigns are undertaken; however, there was a high proportion of non-residents (visiting students, perhaps) in the sample. Again, there was also a high proportion of respondents from the science faculties, and Tabuk has a high provincial profile for its healthcare. This may have had an effect on the answers. Another aspect could be that the questions were less specifically 'medical' and this study's participants were more confident answering them. 


\section{Conclusion}

This study explored the awareness of diabetes mellitus and its characteristics among people from the University of Tabuk. Knowledge of diabetes indicators was encouraging, and, given that there is a high turnover of students on any campus, the administration's periodic diabetes awareness programs are of value in recognising the implications of a disease with a high-risk factor among Arabs. It was indicative that people with higher risk factors related to the disease were aware of these implications. There were no specific limitations to this study that differed from similar studies undertaken on public awareness on a specific factor, and there is no reason to expect that similar results would not be forthcoming from a similar population. Whilst recent Saudi studies of diabetes awareness called for more frequent campaigns by the relevant agencies, there is some evidence of increased awareness, and this research has no hesitation for calling for continued resources being applied to combat the high incidence of diabetes in Saudi Arabia. Diabetes is not a communicable disease such as a coronavirus, so therefore individuals should be aware of genetic risk and adjust their lifestyles accordingly.

\section{Conflicts of Interest}

The author declares no conflicts of interest regarding the publication of this paper.

\section{References}

[1] Hur, S., Cropley, J. and Suter, C. (2017) Paternal Epigenetic Programming: Evolving Metabolic Disease Risk. Journal of Molecular Endocrinology, 58, R159-R168. https://doi.org/10.1530/JME-16-0236

[2] Alzaheb, R. and Altemani, A. (2018) The Prevalence and Determinants of Poor Glycemic Control among Adults with Type 2 Diabetes Mellitus in Saudi Arabia. Diabetes, Metabolic Syndrome and Obesity: Targets and Therapy, 11, 15-21. https://doi.org/10.2147/DMSO.S156214

[3] Apicella, M., Campopiano, M., Mantuano, M., Mazoni, L., Coppelli, A. and Del Prato, S. (2020) COVID-19 in People with Diabetes: Understanding the Reasons for Worse Outcomes. Lancet Diabetes and Endocrinology, 8, 782-792. https://doi.org/10.1016/S2213-8587(20)30238-2

[4] Alshareef, R., Al Zahrani, A., Alzahrani, A. and Ghandoura, L. (2020) Impact of the COVID-19 Lockdown on Diabetes Patients in Jeddah, Saudi Arabia. Diabetes and Metabolic Syndrome: Clinical Research and Reviews, 14, 1583-1587. https://doi.org/10.1016/j.dsx.2020.07.051

[5] International Diabetes Foundation (2020) About Diabetes. https://idf.org/aboutdiabetes/what-is-diabetes.html

[6] International Diabetes Foundation (2020b) Middle East and North Africa. https://idf.org/our-network/regions-members/middle-east-and-north-africa

[7] General Authority for Statistics (2018a) Household Health Survey 2018, Tables 2-2 (Population), 2-3 (Saudi Nationals). https://www.stats.gov.sa/en/965

[8] United States Department of Health and Human Services. Centers for Disease Con- 
trol and Prevention (2019) CDC in Saudi Arabia.

https://www.cdc.gov/globalhealth/countries/saudi arabia/pdf/Saudia-arabia Factsh eet.pdf

[9] Hamoudi, R., Sharif-Askari, N., Sharif-Askari, F., Abusnana, S., Aljaibeji, H., Taneera, J. and Sulaiman, N. (2019) Prediabetes and Diabetes Prevalence and Risk Factors Comparison between Ethnic Groups in the United Arab Emirates. Scientific Reports, 9, Article No. 17437. https://doi.org/10.1038/s41598-019-53505-7

[10] Al-Khudair, D. (2020) Saudis Move to Fight Diabetes, the Silent Killer. Arab News. https://www.arabnews.com/node/1759801/saudi-arabia

[11] International Diabetes Foundation (2020) Discover Diabetes: Warning Signs. https://worlddiabetesday.org

[12] Diabetes UK (2020) Diabetes Facts. https://www.diabetes.org.uk/guide-to-diabetes/enjoy-food/eating-with-diabetes/wh at-is-a-healthy-balanced-diet/quiz-what-do-you-already-know-about-diabetes

[13] Fitzgerald, J., Funnell, M., Anderson, R., Nwankwo, R., Stansfield, R. and Piatt, G. (2016) Validation of the Revised Brief Diabetes Knowledge Test (DKT2). Diabetes Educator, 42, 178-187. https://doi.org/10.1177/0145721715624968

[14] Alanazi, F., Alotaibi, J., Paliadelis, P., Alqarawi, N., Alsharari, A. and Albagawi, B. (2018) Knowledge and Awareness of Diabetes Mellitus and Its Risk Factors in Saudi Arabia. Saudi Medical Journal, 39, 981-989. https://doi.org/10.15537/smj.2018.10.22938

[15] Alharthi, A., Althobaiti, K. and Alswat, K. (2018) Gestational Diabetes Mellitus Knowledge Assessment among Saudi Women. Open Access Macedonian Journal of Medical Sciences, 6, 1522-1526. https://doi.org/10.3889/oamjms.2018.284

[16] Mujammami, M., Alodhayani, A., AlJabri, M., Alanazi, A., Alanazi, S., Alanazi, A. and Ekhzaimy, A. (2020) Knowledge, Awareness and Perceptions of Diabetes Mellitus among the Saudi Population. Journal of Comparative Effectiveness Research, 9, 413-422. https://doi.org/10.2217/cer-2019-0137

[17] Alramadan, M., Magliano, D., Almigbal, T., Batais, M., Afroz, A., Alramadhan, H., Mahfoud, W., Alragas, A. and Billah, B. (2018) Glycaemic Control for People with Type 2 Diabetes in Saudi Arabia-An Urgent Need for a Review of Management Plan. BMC Endocrine Disorders, 18, 62. https://doi.org/10.1186/s12902-018-0292-9

[18] Index Mundi (2020) Diabetes Prevalence (\% of Population Ages 20 to 79)—Country Ranking.

[19] Gosadi, I., Alamri, A., Saleh, R., Almutairi, B., Batais, M. and Alamri, N. (2020) Preference of Sweeteners among Saudi Diabetes Patients from a Tertiary Health Care Centre in Riyadh, Saudi Arabia. Saudi Journal of Biological Sciences, 27, 947-952. https://doi.org/10.1016/j.sjbs.2020.01.022

[20] Alqahtani, F., Aleanizy, F., Mohamed, R., Alanazi, M., Mohamed, N., Alrasheed, M., Albanmy, N. and Alhawassi, T. (2019) Prevalence of Comorbidities in Cases of Middle East Respiratory Syndrome Coronavirus: A Retrospective Study. Epidemiology and Infection, 147, e35. https://doi.org/10.1017/S0950268818002923

[21] Creswell. J.W. and Creswell, J.D. (2017) Research Design: Qualitative, Quantitative, and Mixed Methods Approaches. 4th Edition, Sage, Newbury Park.

[22] Quacquarelli Symonds (QS) Top Universities (2020) University of Tabuk. https://www.topuniversities.com/universities/university-tabuk

[23] General Authority for Statistics (2018) Household Health Survey 2018, Tables 2-2 (Population), 2-3 (Saudi Nationals). https://www.stats.gov.sa/en/965 
[24] General Authority for Statistics (2018) Year Book: Chapter 4 Education and Training, Table 4-7 2(4). https://www.stats.gov.sa/en/1010-0

[25] Gravetter, F. and Wallnau, L. (2015) Statistics for the Behavioral Sciences. 10th Edition, Cengage/Wadsworth, Boston. 